\title{
INFLUENCE OF UNSCHEDULED STOP AND DWELL TIME OF MINIBUS PUBLIC TRANSPORT ON TRANSIT TIME IN KANO METROPOLIS
}

\author{
M. N. Ibrahim ${ }^{1, *}$ and H. M. Alhassan² \\ 1, 2, Department of Civil Engineering, Bayero University, Kano, Kano State, NIGERIA \\ E-mail addresses: ${ }^{1}$ mnibrahim.civ@buk.edu.ng, ${ }^{2}$ hmalhassan.civ@buk.edu.ng
}

\begin{abstract}
Minibus has been one of the modes of public transport in Nigerian cities. Despite its positive impact on urban mobility demand, it is however, associated with some problems which make its service ineffective. This study explores the operating characteristics of minibus public transport in Kano metropolis. It also examines the influence of unscheduled random stops and dwell times of minibus on passengers' transit time. Data were collected on the number of random stop, dwell time per stop, and travel time from route's origin to destination using an in-vehicle observation technique. Four major routes on which minibuses operate were used for the study. Finding from this study revealed that minibus public transport in Kano city is characterized by recurring unscheduled random stops and long dwell time. Across the routes studied, the total number of unscheduled stops ranges from 18 to 23 per trip while the cumulative dwell time per trip constitutes 40 to $60 \%$ of the transit time leading to increase in overall passenger's travel time, with attendant delay to the users. A weak correlation exists between the number of unscheduled stops and transit time, indicating a less influence on the transit time. However, a strong correlation exists between dwell time during stops and travel time which is an indication of a substantial influence on transit time. Further analysis revealed that variations of recurring unscheduled stops and dwell times account for about $74 \%$ of variability in minibus transit time. Finding from test of significance at $\alpha=0.05$ revealed $p$ values of 0.845 and 7.34E-43 for number of stop and dwell time, respectively. This suggests that the number of stop does not influence the transit time significantly; whereas, the dwell time influences the transit time significantly. This implies that increase in passengers' transit time is substantially due to the long dwell time during unscheduled random stop rather than the number of stop itself.
\end{abstract}

Keywords: Minibus, public transport, unscheduled stop, dwell time, transit time

\section{INTRODUCTION}

Globally, efficient public transport has been a key challenge in many cities, and is more pronounced in developing countries. In Nigeria, lack of some better means of urban public transport modes, such as highcapacity buses and light rail transit that are capable of moving a large number of people at a time adds to the problem. In Kano city, the common modes of public transport are minibuses; having a seating capacity of between 10 and 14 passengers, taxicabs, and tricycles. Among these modes, a considerable fraction of public transport users in Kano city utilizes minibuses for their daily trips due to their low fare and availability on a particular route [1]. This makes minibus an important contributing mode of public transport in Kano metropolis.

Despite the positive impact of minibuses public transport mode in the city's mobility demand; it is however, associated with some problems which make its service ineffective. One of the major problems associated with their operation is recurring unscheduled random stops to pick up or drop off passengers. Unscheduled random stops are referred to as those stops made by bus public transport

${ }^{*}$ Corresponding author, tel: $+234-803-686-6293$ 
operators to pick up or drop off passengers at random points along a route other than the designated bus stops. A study on minibus public transport operating routes in Kano city established that minibus stop-time interval ranges from 0.82 to 1.04 minutes [1]. This implies that the minibuses make a stop within a short interval; which is an indication of recurring random stops. Frequent unscheduled stops by bus public transit operators have been identified as a contributing factor to long transit time $[2,3]$. It was revealed that recurring stop could influence transit time reliability and has been identified as a significant factor used in the assessment of transit quality [4]. Likewise, transit disruptions could have a significant impact resulting to commute alterations and lengthen delays during hazardous events [5].

One of the characteristics of minibus operators in Kano city is that they tend to stop at any point along their route randomly once they sight a person or a group of people waiting by the road side without even knowing their intent. Likewise, the operators stop randomly upon a request by an onboard passenger to alight from the bus. In either case, the dwell time spent to pick up intending boarder (and/or pursuing for passengers) or allow for alighting passenger, depends on the operator's discretion. Bus dwell time is referred to as the time spent by a bus for a passenger to alight or board, inclusive of time to open and close the bus door [6] and it is regarded as the primary component of bus travel time [7-10].

Frequent random stops and their associated dwell times affect transit time, making it difficult for the passengers to arrive their destinations as scheduled. This situation leads to unreliable takeoff and arrival times which are deemed as the foremost factors discouraging people from using such mode of transport [11].

Generally, the desire of public transit users is arriving at their respective destinations as expected. It was demonstrated that passengers' arrival at destinations as anticipated has been shown to be among the essential attributes of transit service; and further stops and in-vehicle dwell times result in high disutility [12]. Further, long dwell time at bus terminals is the main problem suffered by users of low-capacity buses [13]. This implies that the dwell times, particularly due to frequent unscheduled stops add to the actual transit time. This could in turn delay the users with resulting effect of making the mode inefficient and less attractive. It was asserted that bus transit time influences service attractiveness and system efficiency [14]. Thus, longer transit time would make the service unreliable; as shorter transit time and timely arrival are deemed as key indicators of service reliability [15-17]. In addition to the longer transit time experienced by passengers as a result of minibus operators' unscheduled random stops associated with long dwell time; it was asserted that INDISCRIMINATE activities and reckless operation of these drivers category, generate considerable noise emission [18]. This could be hazardous to other road users as well as land-uses' occupants within the vicinity of the road.

It is thus evident that recurring unscheduled random stops by minibus public transport operators and the associated dwell times incurred during the stops increase transit time with attendant delays to passengers. One way to reduce the minibus transit time due to unscheduled random stops is to devise the means of minimizing the recurring stops and dwell time during the stop. This would eventually improve the system efficiency and reliability to a large extent [19]. In order to devise an approach towards minimizing the problems associated with the minibus public transport system in our cities, especially, those relating to unscheduled stops and dwell times; it is desirable to explore the current operating characteristics of the system and equally evaluate the influence of these variables on the transit time. Findings to be deduced from this investigation could provide useful information that would allow for proper planning towards improving the services of minibus public transport in Kano metropolis and other Nigerian cities with similar operating characteristics. This could eventually make their operation more reliable. Further, the finding could be used to justify a proposal for the provision of efficient alternative public transport modes in Kano and other Nigerian cities. Hence, this study explores the influence of unscheduled random stops and the associated dwell times of minibus public transport on transit time in Kano city, Nigeria.

\section{METHODOLOGY}

\subsection{Study Area}

This study was conducted in Kano, a commercial city in the northern part of Nigeria. It is the second most populous city in Nigeria with an estimated population of over 3.5 million [20]. This study utilized four major (multi-lane) roads within Kano city on which minibus public transport operate. Included among the chosen are; Gwarzo, Katsina, Maiduguri, and Zaria roads. 
Gwarzo, Katsina, Maiduguri, and Zaria road sites originate from Rijiya Zaki, Dawanau, Mariri, and $\mathrm{Na}$ 'ibawa bus terminals, respectively, and collectively terminate at Yankura terminal. The studied routes are designated as Rijiyar Zaki - Yankura (Route 1), Dawanau - Yankura (Route 2), Mariri - Yankura (Route 3), and Na'ibawa - Yankura (Route 4), respectively. While Rijiyar Zaki, Dawanau, Mariri, and $\mathrm{Na}$ 'ibawa terminals serve as origins for Routes 1, 2, 3 , and 4, respectively; Yankura serves as common final destination for all the routes and vice versa. Routes 1, 2, 3, and 4 traverse the western, northern, eastern, and southern parts of Kano city, respectively. The approximate lengths of Routes 1, 2, 3, and 4 are $11.5 \mathrm{~km}, 14.2 \mathrm{~km}, 14.7 \mathrm{~km}$, and $12.6 \mathrm{~km}$, respectively. The basis for the choice of these routes out of the many in the city is that they are particularly in good condition and attract substantial number of minibus operators. They also traverse a mixture of land-use areas comprising of business, institutional, residential, and so forth.

\subsection{Data Collection}

Data for this research were generated through field observation. The data were collected using in-vehicle observation technique. In the course of generating the data, three variables were observed by an invehicle observer; the travel time ( $\Pi$ ) from a route's origin to its final destination, number of stops (NS), and minibus dwell time per stop (DT). Usually, the minibus makes a stop to pick up, drop off or search passengers. To collect the data on the said variables, the observer boarded a randomly selected bus from the study route's origin to its final destination and vice versa.

The travel time was estimated as the interval between the observer boarding time at route's origin and the drop off time at the final destination. The number of stops made between the origin and the final destination of a route were observed by making a record of each stop on a data sheet. The dwell time incurred by the bus during each of the stops is taken as the interval between the moments when the bus made a stop at a particular point and when it took-off from that point. This measurement was made with the aid of a stopwatch by starting timer as soon as the bus stopped; and immediately the bus took-off, the observer stopped the timer. The interval between the two moments was then recorded against that particular stop as the dwell time. Subsequently, the stop watch was reset and the process repeated for further stops along the route.

The data collection on the input variables was conducted on both directions of traffic for the routes used in this work. On each of the study routes, data were collected for three different periods per day; morning, afternoon, and evening for a total duration of seven days. Data for the morning, afternoon, and evening periods were observed from 7 am to 12 noon, 12 noon to $4 \mathrm{pm}$, and $4 \mathrm{pm}$ to $8 \mathrm{pm}$, respectively. Observations for a particular period of a day were made within the designated hours. The entire data were collected on typical week and weekend days during good weather condition.

Other variables deemed important in this study were derived from the field observed data. These include; running time (RT), ratio of dwell time to running time (DT/RT), and ratio of dwell time to travel time (DT/TT). These variables were derived for the purpose of evaluating the characteristics of the minibus public transport system in the study area. Further analyses were performed with a view to evaluate the influence of NS and DT on $\pi$. A correlation analysis was conducted between $\Pi \mathrm{T}$ and both NS and DT. This was carried out to examine the degree of correlation between $T T$ and NS, and $T T$ and DT. Likewise, a multivariate analysis was performed to evaluate the variability of $\Pi$ due to changes in both NS and DT. This analysis would reveal the extent of significance of variability of NS and DT on that of $\pi$.

\section{RESULTS AND DISCUSSIONS}

Results on minibus operating characteristics in the study area and influence of unscheduled random stop and dwell time on transit time are presented and discussed as follows.

\subsection{Operating Characteristics of Minibus Public Transport in Kano Metropolis}

Minibuses used for public transport in Kano city are usually of low occupancy, having a seating capacity of between 10 and 14 passengers. The operating characteristics of the minibuses considered are; transit time, amount of recurring stops to pick up or drop off passengers, and dwell time during the stops. The proportion of the dwell times relative to the bus running and total transit times between route's origin and destinations were also examined. The variations of these variables across the week and weekend days were evaluated. Figures 1 through 4 depict the 
variations of mean daily travel time $(T T)$, number of stop (NS), and bus dwell time (DT) per trip for routes 1 to 4 , respectively.

An examination of Figures 1 to 4 with regard to daily variations of travel time indicates that for most of the mean daily travel times (TT), the week days recorded

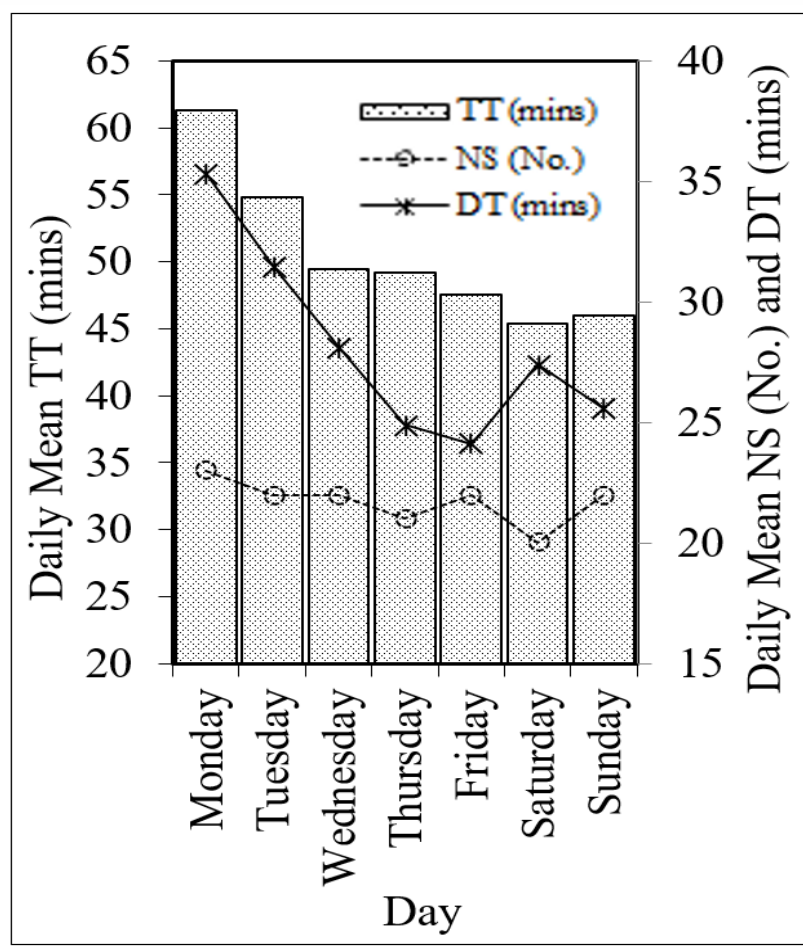

Figure 1: Variation of TT with NS and DT for Route 1

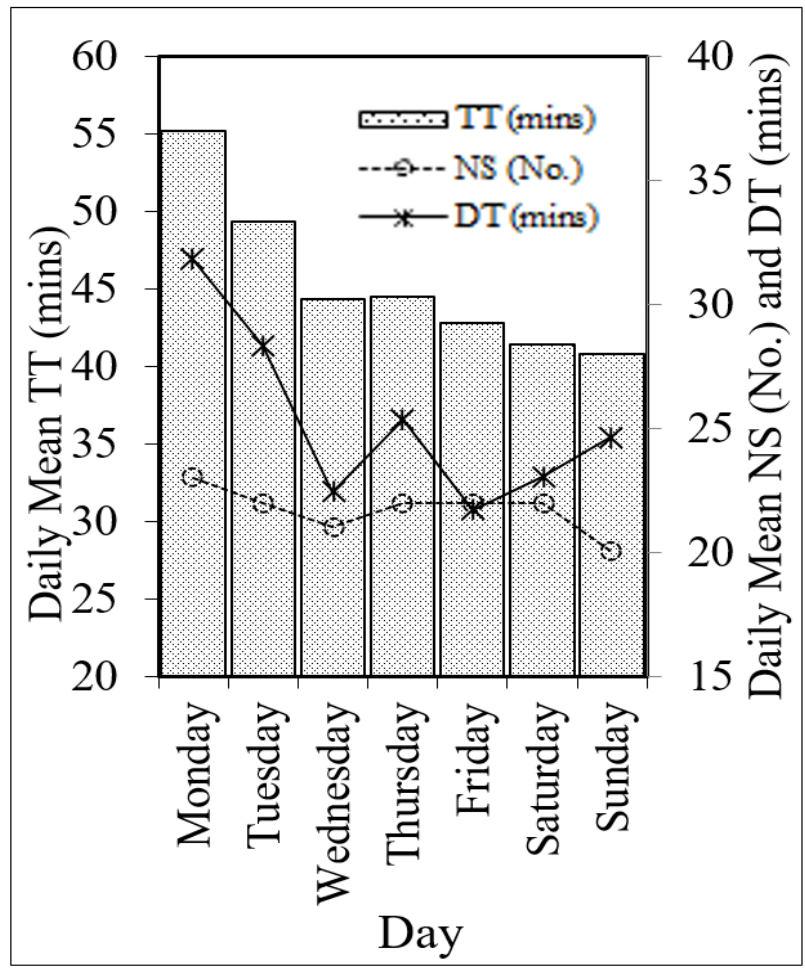

Figure 3: Variation of TT with NS and DT for Route 3 longer estimates as compared to the weekend days. This is not surprising as there are usually more activities and desire to make trips within the weekdays, such as trips for work, school, hospital, and so forth.

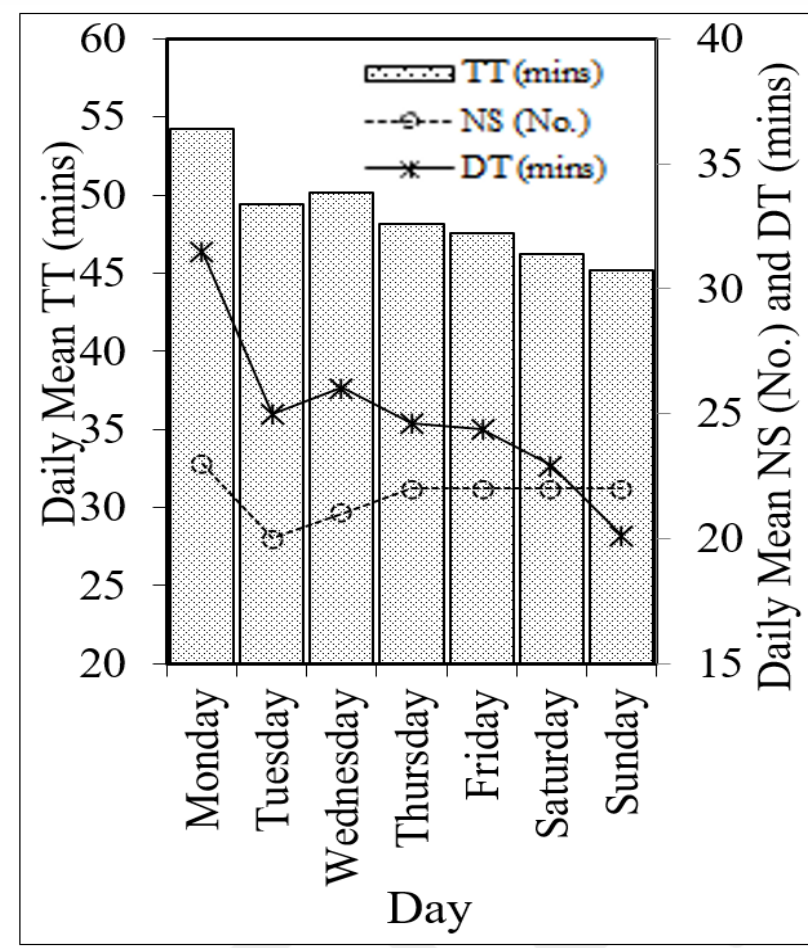

Figure 2: Variation of TT with NS and DT for Route 2

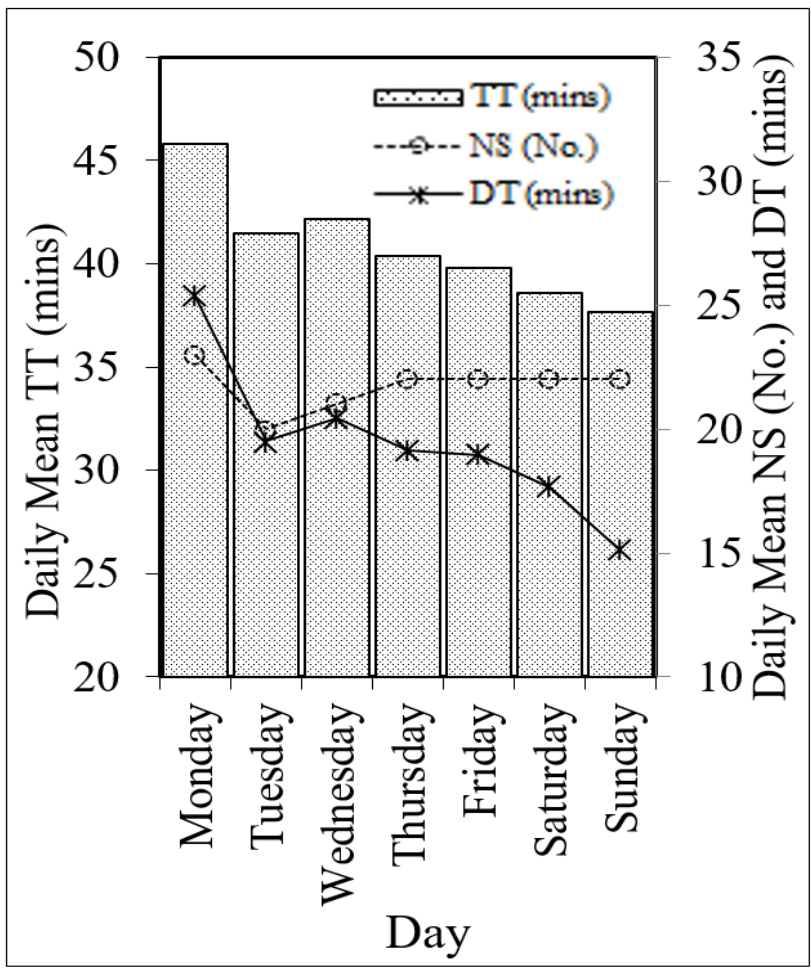

Figure 4: Variation of TT with NS and DT for Route 4 
During the weekend days, trips, such as for work, school and their likes decline relative to those on week days. Hence, the reason for the relative shorter travel times on these days. On the relationship between the daily mean $\mathrm{TT}$ and each of NS and DT, it can be deduced that the number of stops account for little variations in the travel times as indicated by relatively flat line representing the NS. On the other hand, longer TT appears to be associated with lengthy DT. This is clearly shown by the steep linear plot representing the dwell times, which in most cases resulted in higher travel times estimates. This finding implies that longer transit times are more associated with longer dwell times during a stop than the stop itself. The trend exhibited seems to be similar for all the four routes studied as depicted in Figures 1 through 4. Thus, the implication of the long dwell times by the minibus operators during the unscheduled stops leads to increase in transit time with attendant negative impacts on the passengers' schedules. It could therefore be said that minibus public transport system in Kano city is characterized by frequent unscheduled random stops and long dwell times during the stops.

The dwell time (DT) associated with the minibus unscheduled stops was further evaluated relative to the bus running time (RT) and travel time from route's origin to destination. Two parameters were derived; ratios of dwell time to running time (DT/RT) and dwell time to travel time (DT/TT). This analysis was made in order to examine the extent of proportion of dwell time incurred during a stop to either pick up or drop off a passenger. These were determined based on daily mean estimates for the four routes as presented in Tables 1 to 4 .

Table 1: Ratio of Dwell Time to Running and Travel Times for Route 1

\begin{tabular}{lccccc}
\hline Day & $\begin{array}{c}\mathrm{TT} \\
\text { (mins) }\end{array}$ & $\begin{array}{c}\text { DT } \\
\text { (mins) }\end{array}$ & $\begin{array}{c}\mathrm{RT} \\
(\mathrm{mins})\end{array}$ & $\begin{array}{c}\text { DT/RT } \\
(\%)\end{array}$ & $\begin{array}{c}\mathrm{DT} / \mathrm{TT} \\
(\%)\end{array}$ \\
\hline Monday & 61.28 & 35.35 & 25.93 & 136 & 58 \\
Tuesday & 54.84 & 31.49 & 23.35 & 138 & 58 \\
Wednesday & 49.43 & 28.14 & 21.29 & 134 & 57 \\
Thursday & 49.21 & 24.89 & 24.31 & 102 & 51 \\
Friday & 47.51 & 24.10 & 23.41 & 103 & 51 \\
Saturday & 45.34 & 27.39 & 17.95 & 154 & 60 \\
Sunday & 45.96 & 25.60 & 20.35 & 125 & 56 \\
\hline
\end{tabular}

Table 2: Ratio of Dwell Time to Running and Travel Times for Route 2

\begin{tabular}{lccccc}
\hline Day & $\begin{array}{c}\text { TT } \\
\text { (mins) }\end{array}$ & $\begin{array}{c}\text { DT } \\
\text { (mins) }\end{array}$ & $\begin{array}{c}\text { RT } \\
(\text { mins })\end{array}$ & $\begin{array}{c}\text { DT/RT } \\
(\%)\end{array}$ & $\begin{array}{c}\text { DT/TT } \\
(\%)\end{array}$ \\
\hline Monday & 54.21 & 31.48 & 22.73 & 143 & 58 \\
Tuesday & 49.39 & 25.00 & 24.39 & 103 & 51 \\
Wednesday & 50.16 & 26.03 & 24.13 & 107 & 52 \\
Thursday & 48.18 & 24.60 & 23.58 & 111 & 52 \\
Friday & 47.52 & 24.38 & 23.14 & 108 & 52 \\
Saturday & 46.20 & 22.94 & 23.26 & 99 & 50 \\
Sunday & 45.21 & 20.12 & 25.08 & 82 & 45 \\
\hline
\end{tabular}

Table 3: Ratio of Dwell Time to Running and Travel Times for Route 3

\begin{tabular}{lccccc}
\hline Day & $\begin{array}{c}\mathrm{TT} \\
\text { (mins) }\end{array}$ & $\begin{array}{c}\text { DT } \\
\text { (mins) }\end{array}$ & $\begin{array}{c}\text { RT } \\
\text { (mins) }\end{array}$ & $\begin{array}{c}\text { DT/RT } \\
(\%)\end{array}$ & $\begin{array}{c}\text { DT/TT } \\
(\%)\end{array}$ \\
\hline Monday & 55.15 & 31.81 & 23.34 & 136 & 58 \\
Tuesday & 49.35 & 28.34 & 21.01 & 135 & 57 \\
Wednesday & 44.28 & 22.40 & 21.88 & 102 & 51 \\
Thursday & 44.48 & 25.33 & 19.16 & 134 & 57 \\
Friday & 42.76 & 21.69 & 21.07 & 103 & 51 \\
Saturday & 41.36 & 23.04 & 18.32 & 125 & 56 \\
Sunday & 40.81 & 24.65 & 16.16 & 153 & 60 \\
\hline
\end{tabular}

Table 4: Ratio of Dwell Time to Running and Travel Times for Route 4

\begin{tabular}{lccccc}
\hline Day & $\begin{array}{c}\text { TT } \\
\text { (mins) }\end{array}$ & $\begin{array}{c}\text { DT } \\
\text { (mins) }\end{array}$ & $\begin{array}{c}\text { RT } \\
\text { (mins) }\end{array}$ & $\begin{array}{c}\text { DT/RT } \\
(\%)\end{array}$ & $\begin{array}{c}\text { DT/TT } \\
(\%)\end{array}$ \\
\hline Monday & 45.78 & 25.33 & 20.45 & 128 & 56 \\
Tuesday & 39.77 & 18.95 & 20.82 & 92 & 48 \\
Wednesday & 42.14 & 20.43 & 21.71 & 93 & 48 \\
Thursday & 40.36 & 19.14 & 21.22 & 96 & 48 \\
Friday & 41.45 & 19.50 & 21.95 & 89 & 47 \\
Saturday & 38.58 & 17.65 & 20.93 & 84 & 46 \\
Sunday & 37.68 & 15.11 & 22.57 & 68 & 40 \\
\hline
\end{tabular}

From the results presented in Tables 1 through 4, it can be deduced that based on the ratios of the waiting to the bus running times per trip, the dwell times are in most instances higher than the running times. On the lower side, the dwell times are up to two-third of the running times; while on the higher side, the values exceeded the running times by more than $50 \%$ (DT/RT > 150\%). This finding is a clear indication of low running time with a resulting long journey time due to frequent unscheduled stops and long dwell times during the stops. A similar trend was exhibited by the ratio of dwell to travel times. Across the four routes, the proportion of the dwell times 
relative to the total transit time ranges from 40 to $60 \%$. This high estimate suggests long dwell times during stops to pick up or drop off passengers and thus results in longer transit time to the passengers. These characteristics revealed that the operating system of minibus public transport in Kano city is inefficient as passengers are delayed excessively due to long dwell times incurred during unscheduled stops.

If the excessive delay experienced by users of minibus public transport in Kano city is to be expressed in terms of monetary values, it could amount to a considerable loss. Hence, to safeguard against this, a good policy needs to be put in place to improve the operational characteristics of the minibuses (of which findings from this study could contribute in developing such a policy).

\subsection{Influence of Unscheduled Stops and Dwell Time on Transit Time}

In order to assess the effects of minibus unscheduled random stop and dwell time during such stops on transit time, a statistical analysis was performed. Two forms of analyses were carried out. Firstly, a correlation analysis between travel time (TT) and both the number of stops (NS) and dwell time (DT) aimed at examining the degree of correlation between $\Pi$ and NS, and $\Pi$ and DT. Secondly, a multivariate analysis was performed to evaluate the variability of TT due to changes in both NS and DT as well as to assess the extent of their significance.

A total number of 168 data points were used for each of the analyses. These points were derived from 3 periods (morning, afternoon, and evening) observations on 2 traffic directions of 4 routes for 7 days $(3 \times 2 \times 4 \times 7=168)$. The result of the correlation analysis is presented in Table 5 .
Table 5: Correlation Matrix of TT, NS and DT

\begin{tabular}{cccc}
\hline Variables & $T \mathrm{~T}$ & $\mathrm{NS}$ & $\mathrm{DT}$ \\
\hline $\mathrm{TT}$ & 1.000 & 0.233 & 0.861 \\
$\mathrm{NS}$ & 0.233 & 1.000 & 0.511 \\
$\mathrm{DT}$ & 0.861 & 0.511 & 1.000 \\
\hline
\end{tabular}

The result presented in Table 5 shows that the correlation between travel time $(T T)$ and number of unscheduled stops (NS) is weak for having a correlation coefficient of 0.233 . This value implies a weak correlation between NS and $\Pi \pi$ as correlation coefficients of between 0 and $0.30,0.31$ and 0.59 , and 0.60 and 1.00 indicate a weak, medium, and strong correlations, respectively [21, 22]. The correlation coefficient value between $\Pi$ and NS suggests that the number of stops has less influence on transit time. However, the correlation coefficient of 0.861 between $\Pi$ and DT indicates that a strong correlation exists between these variables. This implies that dwell time incurred during an unscheduled stop has a high influence on transit time. On comparing the influence of NS and DT on TT, the finding indicates that DT has more influence on $T$ than NS.

In order to have a clear insight on the influence of NS and DT on TT, a multivariate analysis was performed with $\Pi$ as dependent variable while NS and DT as predictors. The analysis is intended to specifically evaluate the degree of influence of NS and DT on TT (i.e. to examine how well transit time respond to variations in the magnitude of the unscheduled stop and dwell time). Similar approach was utilized in a previous study [23]. The analysis was also performed at a significance level of $95 \%(\alpha=0.05)$. The results of this analysis are presented in Tables 6 (a, $b$, and $c)$.

Table 6: Multivariate Analysis Output

(a) Regression Statistics

\begin{tabular}{|c|c|}
\hline Multiple R & 0.861 \\
\hline R Square & 0.741 \\
\hline Adj. R Square & 0.738 \\
\hline Standard Error & 5.167 \\
\hline Observations & 168 \\
\hline
\end{tabular}

(b) ANOVA

\begin{tabular}{lcrrrl}
\hline & Df & \multicolumn{1}{c}{ SS } & MS & F & Sig. F \\
\hline Regression & 2 & 12630.42 & 6315.21 & 236.55 & $3.46 \mathrm{E}-49$ \\
Residual & 165 & 4405.02 & 26.70 & & \\
Total & 167 & 17035.44 & & & \\
\hline
\end{tabular}


(c) Coefficients

\begin{tabular}{lcccccc}
\hline \multirow{2}{*}{ Model } & Coefficients & $\begin{array}{c}\text { Standard } \\
\text { Error }\end{array}$ & t Stat & P-value & $\begin{array}{c}\text { Lower } \\
95.0 \%\end{array}$ & $\begin{array}{c}\text { Upper } \\
95.0 \%\end{array}$ \\
\hline Intercept & 19.096 & 2.216 & 8.615 & $5.4 \mathrm{E}-15$ & 14.719 & 23.472 \\
NS & -0.026 & 0.134 & -0.196 & 0.845 & -0.292 & 0.239 \\
DT & 1.135 & 0.060 & 18.796 & $7.34 \mathrm{E}-43$ & 1.016 & 1.255 \\
\hline
\end{tabular}

The analysis output presented in Table 6 resulted in a coefficient of determination $\left(R^{2}\right)$ of 0.741 which indicates that $\Pi$ is well influenced by NS and DT. Furthermore, based on the $\mathrm{R}^{2}$ value, the influencing variables account for approximately $74 \%$ of the variability in $\Pi$. This demonstrates that $\Pi$ is reasonably sensitive to the influence of NS and DT. Similarly, the value of the coefficient of multiple correlation (Multiple $\mathrm{R}=0.861$ ) affirms the reasonable influence of unscheduled stops and dwell time on passengers' transit time.

On the account of individual influence of NS and DT on the variability in $\pi$, the DT was found to contribute significantly to the variation in $\Pi$. This is indicated by its $p$-value (7.34E-43) from test of significance, which is much lower than 0.05 as shown in Table 6 (c). However, NS was found to have less significant contribution to the variation in $\pi$; as its $p$ value was found to be 0.845 , which is higher than 0.05. This indicates that based on the data used for this study, transit time is mostly influenced by the amount of dwell time during an unscheduled stop rather than the number of stops.

\section{CONCLUSIONS}

Based on the investigations conducted, the key findings from this study are summarized as follows:

(i) The operation of minibus public transport system in Kano city is characterized by recurring unscheduled stops and long dwell times. Across the routes studied, the amount of unscheduled stops ranges from 18 to 23 stops per trip while the cumulative mean dwell time per trip constitutes 40 to $60 \%$ of the passenger's transit time leading to an increase in travel time with attendant delay to passengers.

(ii) A weak correlation exists between the amount of unscheduled stops and transit time, indicating a less influence on the transit time. However, a strong correlation exists between dwell time during stops and travel time which is an indication of a substantial influence on transit time. (iii) Variations of recurring unscheduled stops and dwell times account for approximately $74 \%$ of variability in transit time associated with minibus public transport mode in Kano metropolis. An analysis of variance indicates that the number of unscheduled stop does not influence transit time significantly, as its p-value ( 0.845$)$ is higher than 0.05 . Whereas, the dwell time influences the transit time significantly, as its p-value (7.34E-43) is much lower than 0.05 . This implies that increase in passengers' transit time is essentially due the long dwell time during unscheduled stop rather than the amount of stop itself.

\section{ACKNOWLEDGEMENT}

The authors wish to acknowledge the effort of A. K. Ramadan, A. M. Musa, and Y. D. Advuruku for their support in the course of data sampling for this work.

\section{REFERENCES}

[1] M. N. Ibrahim and Y. Isma'il, "Estimation of Bus Stops Spacing on Public Transport Routes in Kano Metropolis Using Minibus Stop Time Interval," International Journal of Engineering and Science Invention, vol. 2, pp. 36-44, 2013.

[2] D. Jepson, D. Bitzios, and L. Ferreira, "Enhancing Transit in Tourist Areas through Improved Modeling and Priority Initiatives: Case Study from Australia," Transportation Research Record: Journal of the Transportation Research Board, pp. 38-45, 1999.

[3] K. Owen deVries, "Effects of Bus Stop Consolidation on Transit Speed and Reliability: A Test Case.," PhD Thesis, University of Washington, 2004.

[4] C. Cirillo, L. Eboli, and G. Mazzulla, "On the Asymmetric User Perception of Transit Sservice Quality," International Journal of Sustainable Transportation, vol. 5, pp. 216-232, 2011.

[5] E. Kontou, P. Murray-Tuite, and K. Wernstedt, "Duration of Commute Travel Changes in the Aftermath of Hurricane Sandy Using Accelerated Failure Time Modeling," Transportation 
Research Part A: Policy and Practice, vol. 100, pp. 170-181, 2017.

[6] S. Jaiswal, J. Bunker, and L. Ferreira, "Influence of Platform Walking on BRT Station Bus Dwell Time Estimation: Australian Analysis," Journal of Transportation Engineering, vol. 136, pp. 11731179, 2010.

[7] Y. Hadas and A. A. Ceder, "Optimal Coordination of Public-transit Vehicles Using Operational Tactics Examined by Simulation," Transportation Research Part C: Emerging Technologies, vol. 18, pp. 879-895, 2010.

[8] W. H. Lin and R. L. Bertini, "Modeling Schedule Recovery Processes in Transit Operations for Bus Arrival Time Prediction," Journal of Advanced Transportation, vol. 38, pp. 347-365, 2004.

[9] Q. Meng and X. Qu, "Bus Dwell Time Estimation at Bus Bays: A Probabilistic Approach," Transportation Research Part C: Emerging Technologies, vol. 36, pp. 61-71, 2013.

[10] A. Tirachini and D. A. Hensher, "Bus Congestion, Optimal Infrastructure Investment and the Choice of a Fare Collection System in Dedicated Bus Corridors," Transportation Research Part B: Methodological, vol. 45, pp. 828-844, 2011.

[11] A. Nour, "Quantifying the Impact of Transit Reliability on Users Cost-A Simulation Based Approach," Master Thesis, University of Waterloo, Canada, 2009.

[12] N. Van Oort, "Service Reliability and Urban Public Transport Design," PhD Thesis, Netherlands TRAIL Research School 2011.

[13] M. Napiah and I. Kamaruddin, "Punctuality Index and Expected Average Waiting Time of Stage Buses in Mixed Traffic," WIT Transactions on the Built Environment, vol. 116, pp. 215-226, 2011.

[14] R. L. Bertini and A. M. El-Geneidy, "Modeling Transit Trip Time Using Archived Bus Dispatch
System Data," Journal of Transportation Engineering, vol. 130, pp. 56-67, 2004.

[15] P. Furth and T. Muller, "Service Reliability and Hidden Waiting Time: Insights from Automatic Vehicle Location Data," Transportation Research Record: Journal of the Transportation Research Board, pp. 79-87, 2006.

[16] P. Furth and T. Muller, "Service reliability and optimal running time schedules," Transportation Research Record: Journal of the Transportation Research Board, pp. 55-61, 2007.

[17] N. Shlayan, L. Ratliff, O. Ayubi, and P. Kachroo, "Travel Time Reliability Analysis using Dynamic Message Sign Recordings," in Proceedings: 88th TRB annual meeting, Transportation Research Board, Washington, D.C, 2009.

[18] E. Okonofua, R. Ehigiator-Irughe, and M. Ekun, "Traffic Noise Monitoring at Road Intersections in Urban Settlement: Case Study of Ramat Park Benin City," Nigerian Journal of Technology, vol. 35, pp. 713-717, 2016.

[19] M. M. Elhabiby, A. O. Fikry, H. A. Mahdy, and K. A. Kandil, "Influence of Unscheduled Random Public Bus Stops on Transit Travel Time," Journal of Traffic and Logistics Engineering, vol. 1, pp. 20-24, 2013.

[20] NBS, "Annual Abstract of Statistics," National Bureau of Statistics. Abuja2016.

[21] A. Field, Discovering Statitics Using SPSS: Sage, 2009.

[22] B. G. Susan and B. F. Kristin, "Using SPSS For Windows: Data Analysis and Graphics," ed: Springer, 2013.

[23] A. Al-Kaisy and C. Durbin, "Evaluating New Methodologies for Estimating Performance on Two-lane Highways," Canadian Journal of Civil Engineering, NRC Research Press, vol. 35, pp. 777-785, 2008-08-01 2008. 